\title{
Group Formation Using Friendship Graph in Managing Students' Projects in Educational Settings
}

\author{
Ochilbek Rakhmanov ${ }^{a}$, Abdulwahab Adinoyi Animoku ${ }^{b^{*}}$ \\ ${ }^{a}$ Nile University of Nigeria, Nigeria \\ ${ }^{\mathrm{b}}$ Nile University of Nigeria, Nigeria

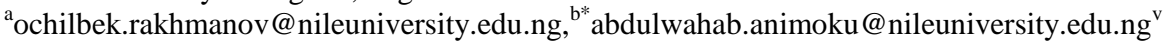

Article History: Received: 10 November 2020; Revised 12 January 2021 Accepted: 27 January 2021; Published online: 5 April 2021

\begin{abstract}
In the literature, there are several group formation methods such as random, self-selected, instructor-selected, and mixed, which have been outlined on how to form groups for effective learning and project completion. There is little empirical research on which of the approaches creates the best student learning experience. In this article, we examine the use of acquaintance and friendship graphs in generating groups to manage projects in a learning environment. This work focuses on freshmen and sophomores from faculty of Natural and Applied Sciences and faculty of Medicine at "Nile university of Nigeria". In creating the friendship graphs for each of the classes, a questionnaire is employed. The responses from the students are transformed into graph input data. The resultant graphs are then analyzed to create the project groups. The performance (measured by group grades) of students in the projects is an evidence that this method of creating groups is effective. Moreover, the project completion time and average score of the projects show improvement in comparison to previous year's groups, which were formed by instructor-selected method. Furthermore, testing our created groups against the normal standard of group formation using a balanced distribution of GPA scores, see [1], indicates that our method passed with $83 \%$. In fact, when each student was presented with the opportunity to choose through voting whether to be within an instructor-selected group with a balanced distribution of GPA scores or a group formed by the friendship graph approach, an overwhelming $78 \%$ chooses the latter
\end{abstract}

Keywords: Acquaintance and friendship graph, social network, group performance, instructor-selected, Group formation

\section{Introduction}

Group and collaborative work have become a central part of learning in any professional settings. As such, educational environment is no exception. In fact, working in groups within the classroom has gained more attention in recent years due to the complexity of problems that are often tackled today in the modern classrooms. Often, students are tasked with the responsibility to work on comprehensive research projects that highlight key aspects of some these multidimensional issues. Due to the short time frame often given to students to tackle this informative research, forming of groups to share responsibilities among members has proven to be effective. Therefore, it is important to understand how best to form the groups for effective and impactful learning.

There are several methods in the literature that have been proposed on various ways to form groups especially in an active learning classroom. These methods include random, instructor-generated, self-selected, and mixed. Each of these methods has been explained in [1] with great details. Here, we present the use of friendship graphs as an effective tool in creating and forming groups used in assigning classroom projects. Although, there are several articles in the literature, for example see $[2,3]$ that have highlighted that close relationships among peers can hinder learning and affect successful completion of projects in work setting. However, there is no consensus on this as other research articles such as that of $[4,5,6,7,15]$ have found that existing friendship among group members enhance better task performance. The inconclusiveness on the effect of friendship on group performance needs more examination with more empirical evidence. The approach and methodology provided in this paper, therein, will be key in forming groups to study the dynamics of friendship/acquaintance groups and measure of performances further.

We adopt the definition of friendship group mentioned in [6], as a group with close interpersonal relationship and preexisting communication among members. Thus, the friendship graph used in our classroom setting involves a graph that represent people as vertices and friendship with undirected edges. An edge exists between two people when at least one of the two students indicates that they know each other. This method of assigning students to groups can easily be extended to any of the approaches highlighted earlier on group formation. Moreover, our approach also makes it easier to form groups in large classes while making sure effective communication is maintained within each group. 
In this study we administer questionnaire to freshmen and sophomore students from Faculty of Natural and Applied Sciences and faculty of Medicine at "Nile university of Nigeria". The graphs obtained thereof, are used to split students into groups with assigned projects as part of their overall grading in fall semester of 2019/2020 academic calendar. More on this in Section 4.

The remaining part of the paper is structured as follows. Section 2 briefly highlights the literature review on this topic. Section 3 reveals the instruments underlying the creation of graphs in this article. In Section 4, we explain in great detail the method of data collection, implementation procedure and analysis of results obtained; and Section 5 concludes.

\section{Literature Review}

In this section we familiarize our readers with some of the existing literature on group formation and application of friendship graph. The first work on the use of friendship network in studying friendship choices among students can be traced to the work of [8]. The author developed a process that brings individuals together that can work harmoniously and function as a unit with maximum efficiency while reducing disruptive tendencies among members.

In $[9,10]$, the authors create an actor-oriented statistical models for friendship groups. They had constructed an expected utility function that maximizes the utility function of an individual actor with respect to friendship.

Furthermore, [6] incorporates a multi-method approach to study the effect of group processes (as a measure of relationship level) on group performance. The result from their analysis shows that friendship groups perform better than acquaintance group on both decision making and motor skills.

In a recent work, [11] focuses on the relationship between academic performance of engineering students in two different countries and their social network graph. Based on the network graph, the authors conclude that social relationships may have a direct impact on academic performance. This article is also a resource for more detailed literature review on team learning and social networks, friendship network, social network and team performance. Interested readers should see [11] and the references therein.

\section{Methods}

Graph: A simple (undirected) graph $\mathrm{G}=(\mathrm{V}, \mathrm{E})$ consists of $\mathrm{V}$, a nonempty set of vertices (or nodes) and $\mathrm{E}$, a set of edges. Each edge has either one or two vertices associated with it, called its endpoints. An edge is said to connect its endpoints [12].

Friendship Graph: We can use a simple graph to represent whether two people know each other, that is, whether they are acquainted, or whether they are friends. Each person in a particular group of people is represented by a vertex. An undirected edge is used to connect two people when these people know each other, when we are concerned only with acquaintanceship, or whether they are friends [12,14].

Degree of vertex: The degree of a vertex in an undirected graph is the number of edges incident from it. The degree of the vertex $\mathrm{v}$ is denoted by $\operatorname{deg}(\mathrm{v})$. In our case, $\operatorname{deg}(\mathrm{v})$ would represent number of persons who mentioned vertex $\mathrm{v}$ as a friend [14].

Coding and library: During visualization and analysis of the graph we used Python programming language with open source library NetworkX [13]. This library can easily process the graph information and produce all necessary tools for further observations and analysis.

\section{Methodology}

The following steps have been performed during development of the methodology:

1. Conduct of the survey.

2. Transformation of raw data into Graph input data.

3. Extraction of information from graph.

4. Technical analysis of formed groups.

5. Testing effectiveness through voting.

\section{Conduct of the Survey}

Ethics and standards: We have strictly followed all ethical standards during the survey and research. All procedures performed in this study involving human participants are in accordance with the ethical standards of the institutional and/or national research committee and with the 1964 Helsinki declaration and its later 
amendments or comparable ethical standards. Informed consent was obtained from all individual participants included in the study.

Selection of the participants: All participants are from Computer science department; one group from 100 level students and other groups are 200 level students.

Procedure: Students are given a plain sheet and were requested to write down their best 3 friends who are classmates. It was optional to write up to 3 names, as some students mentioned only 2 or 1 name, and we had a group of students who didn't mention any name. Students who didn't write down any name on paper are manually acquainted with a person named Nil, which means no friend. Papers with names are then collected and converted to spreadsheet format. We encoded names to keep privacy during research, but names were disclosed to students in order to conduct a voting procedure after the group formations.

\section{Transformation of raw data into graph input data}

Friendship to node-to-node connection. Every student is assumed as one node. If the student has friendship connection with some other student, then an edge is created between these 2 nodes. Hence, for instance, a student whose name was mentioned 3 times, would have 3 edges connected to it. At this point our formed spreadsheet needs to be converted to node-to-node relation format. Figure 1 is a sample representation of conversion from friendship spreadsheet to node-to-node connection. Distance between nodes is constant, 1 unit. Repetitive connections (like John-Mike and Mike-John) counted as 1 connection. Lastly, node-to-node dataset is fed as input for graph formation.

\begin{tabular}{|c|c|c|c|c|c|}
\hline \multirow[b]{2}{*}{ Student } & \multirow[b]{2}{*}{ Friend 1} & \multirow[b]{2}{*}{ Friend 2} & \multirow[b]{2}{*}{ Friend 3} & \multirow{2}{*}{$\begin{array}{l}\text { John } \\
\text { John }\end{array}$} & \multirow{2}{*}{\begin{tabular}{|l|} 
Bob \\
Mike
\end{tabular}} \\
\hline & & & & & \\
\hline John & Bob & Mike & Danny & John & Danny \\
\hline Mike & John & Fred & & Mike & John \\
\hline \multirow[t]{2}{*}{ Ricky } & Nil & & & Mike & Fred \\
\hline & & & & Ricky & Nil \\
\hline
\end{tabular}

Figure 1. Friendship to node-to-node connection

\section{Extraction of Information from Graph}

Figure 2 is pictorial representation of friendship graph for 200 level group. Same representation is obtained for 100 level.

\section{Group Formation}

As mentioned before, the main goal of this study is to find proper method to improve communication between project group members. Following logic "a friend of my friend is also my friend", formation of the groups where every node has at least some connections within group would definitely improve communication quality during project development. To achieve this, we divide the friendship graph into regions. We have used 3 criteria in the formation of the regions:

a. Every node should have at least 1 connection edge

b. No group should have more than 9 nodes

c. There should exist one node with highest degree of connections within every group.

Figure 3 presents the groups for both 100 and 200 level students. Some nodes, which are left out of the groups in Figure 3 are later assigned to some groups which they have better connections to.

\section{Identification of nodes with the highest nodes}

We counted degree for every node, list them in descending order and selected the node with the highest degree from every group. These selected nodes have the highest number of connections within each group, thus can serve as communicators or project coordinators; so, they are assigned as heads of formed project groups. Table 1 shows the summary of 10 students selected at each level and their assigned groups. It can be observed that every student in this group has at least 4 connections, and as we have stated before, groups are formed with at most 8 students in every group. This means every assigned head of group in Table 1 has connections with more than $\% 50$ of the group, which is solving one of main concerns we are addressing, creating strong connection within group.

Table 1. Assignment of the head of groups 


\begin{tabular}{|c|c|c|c|c|c|c|}
\hline & \multicolumn{3}{|c|}{100 LEVEL } & \multicolumn{3}{|c|}{200 LEVEL } \\
\hline & 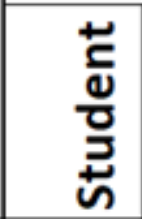 & 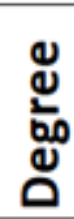 & $\begin{array}{l}\text { 을 } \\
\text { 운 }\end{array}$ & 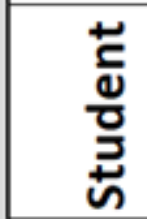 & 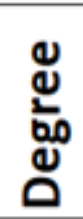 & 을 \\
\hline 1 & AFO & 8 & A & NIL & 11 & $\mathrm{~N}$ \\
\hline 2 & OFM & 7 & & ABA & 5 & $\mathrm{E}$ \\
\hline 3 & SDI & 7 & $B$ & ASJ & 5 & $\mathrm{~F}$ \\
\hline 4 & FGA & 6 & C & FEG & 5 & C \\
\hline 5 & CAM & 5 & & MIA & 4 & $A$ \\
\hline 6 & NGA & 5 & & JDW & 4 & D \\
\hline 7 & AAI & 4 & D & JFM & 4 & \\
\hline 8 & RGI & 4 & $E$ & ZAB & 4 & B \\
\hline 9 & JTS & 4 & & AOM & 4 & \\
\hline 10 & MIN & 4 & & BMO & 4 & \\
\hline
\end{tabular}

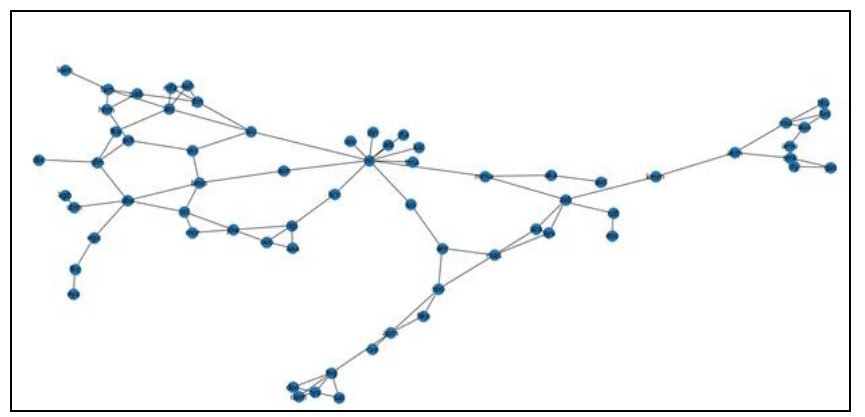

Figure 2. Pictorial representation of 200 level group friendship connection

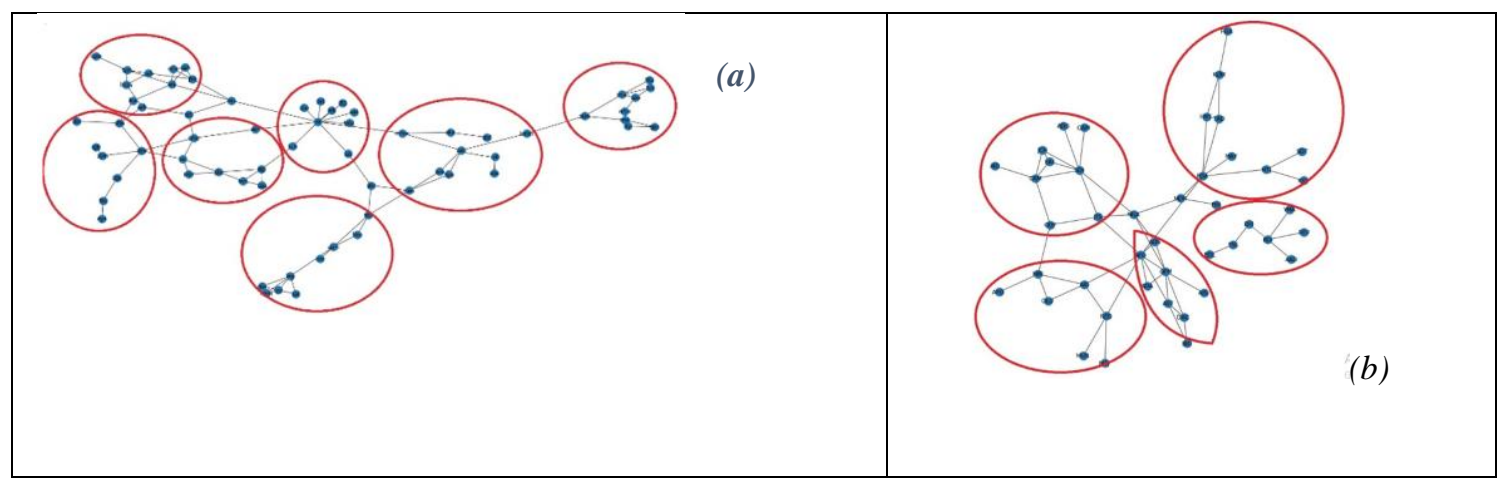

Figure 3. Formation of the groups; (a) 200 level students, (b) 100 level students

Note that within the 200 level we have a student named 'NIL' and as we indicated before, the students who didn't mention any friends are connected to nil, which is why NIL has the highest degree. At this point it is up to 
the course instructor on how to handle this group. We have proposed 2 ways to solve this problem. One is to form a new group for students with nil connections and create an opportunity for them to make new friends; the other is to distribute them to other groups equally. We have chosen the former option in this research.

\section{Technical analysis of formed groups}

The most practiced method of assigning students to groups in an academic environment is the use of academic performance; this is to ensure that all groups are balanced. This thesis was also supported by [1]. Furthermore, [1] points out that an "Instructor-generated" method should use this criterion to produce balanced groups. GPA score classes are reference for this distribution, where we have 3 GPA classes; first, second and third class. Thus, if a group consists of 8 members, then this group should have at least 1 first class member, at least 4 second class members and at most 3 third class members. Based on this, we tested our newly formed groups, formed through friendship. So, we try to answer the aforementioned questions; does the group have at least 1 first class student, at least 4 second class students and at most 3 third class students? Table 2 is a summary of the responses. From the analysis, the ratio of NOs to total is 6 to 36, or 83\% success rate, which is fairly acceptable ratio.

Table 2. Checking for balanced grade distribution criterion for the formed groups

\begin{tabular}{|c|c|c|c|c|c|}
\hline \multirow[b]{2}{*}{ Criteria } & \multicolumn{5}{|c|}{100 Level } \\
\hline & $\mathbf{A}$ & B & $\mathrm{C}$ & D & $\mathbf{E}$ \\
\hline At least 1 First class? & Yes & Yes & Yes & No & Yes \\
\hline At least 4 Second class? & Yes & Yes & Yes & Yes & Yes \\
\hline At most 3 Third class? & Yes & Yes & Yes & No & Yes \\
\hline
\end{tabular}

\begin{tabular}{|c|c|c|c|c|c|c|c|}
\hline \multirow[b]{2}{*}{ Criteria } & \multicolumn{7}{|c|}{200 level } \\
\hline & $\mathbf{A}$ & B & $\mathbf{C}$ & D & $\mathbf{E}$ & $\mathbf{F}$ & $\mathbf{N}$ \\
\hline At least 1 First class? & Yes & Yes & No & Yes & No & Yes & Yes \\
\hline At least 4 Second class? & Yes & Yes & Yes & Yes & Yes & No & Yes \\
\hline At most 3 Third class? & Yes & Yes & Yes & Yes & Yes & No & Yes \\
\hline
\end{tabular}

Testing effectiveness through voting and project submissions

The last experiment we have conducted is to collect the responses of the students to the newly formed groups. We create 2 options; in the first option, we form fairly distributed groups using the criterion outlined in Section 4.3 , the second option involves groups formed through graph. We allow the students to choose one of the options through open voting and $78 \%$ of students select the second option, a very high percentage.

Furthermore, all the projects were submitted before the deadline, compared to $23 \%$ of projects with late submission in the previous semester. Yet, the results of the projects are relatively better when compared to the previous semester, for 200 levels, as the average score of the projects increased by $17 \%$. This is empirical evidence that existing friendships within a group can foster better academic performance. We couldn't conduct such comparison for 100 level students as they were freshmen group.

\section{Results}

The last experiment we have conducted is to collect the responses of the students to the newly formed groups. We create 2 options; in the first option, we form fairly distributed groups using the criterion outlined in Section 4.3 , the second option involves groups formed through graph. We allow the students to choose one of the options through open voting and $78 \%$ of students select the second option, a very high percentage.

Furthermore, all the projects were submitted before the deadline, compared to $23 \%$ of projects with late submission in the previous semester. Yet, the results of the projects are relatively better when compared to the previous semester, for 200 levels, as the average score of the projects increased by $17 \%$. This is empirical evidence that existing friendships within a group can foster better academic performance. We couldn't conduct such comparison for 100 level students as they were freshmen group.

\section{Conclusion}

This paper studies on the use of friendship graph in group formation for assigning projects among university students. The paper also contributes to a growing number of literatures that study on the effect of existing friendship on learning outcome of group members. In line with authors such as [6], we conclude that existing 
friendship among group members has positive effect on the academic performance of students. The summary of the study can be presented in several observations.

Observation 1. The first observation is that students are more likely to choose groups formed through friendship graphs, which will definitely show impact on willingness of students to contribute to the project.

Observation 2. The methodology showed that even if the groups are formed blindly with respect to academic performance, still the GPA distribution was fair enough among the groups.

Observation 3. The groups formed through friendship graphs performed better in terms of submission and the quality of the projects, in comparison to previous session's results.

\section{References}

Baepler, P., Walker, J., Brooks, D. C., Saichaie, K., \& Petersen, C. I. "A guide to teaching in the active learning classroom.” History, research, and practice. Stylus Publishing, LLC, 2016.

Bramel, D., \& Friend, R. "The work group and its vicissitudes in social and industrial psychology." The Journal of applied behavioral science, 23(2), 233-253, 1987.

Homans, G. C. The human group. New Brunswick, 1950.

Baron, R. A., \& Byrne, D. Social psychology: Understanding human interaction Allyn \& Bacon, 1987.

Berkowitz, L. Group standards, cohesiveness, and productivity. Human Relations 7(4), 509-519, 1954.

Jehn, K. A., \& Shah, P. P. "Interpersonal relationships and task performance: An examination of mediation processes in friendship and acquaintance groups.” Journal of personality and social psychology, 72(4), 775, 1997.

Mesmer-Magnus, J. R., \& DeChurch, L. A. "Information sharing and team performance: A meta-analysis." Journal of applied psychology, 94(2), 535, 2009.

Moreno, J. L. Who shall survive? A new approach to the problem of human interrelations, 1934.

Leenders, R. T. A. "Evolution of friendship and best friendship choices." Journal of Mathematical Sociology, 21(1-2), 133-148, 1996.

Van de Bunt, G. G., Van Duijn, M. A., \& Snijders, T. A. Friendship networks through time: An actororiented dynamic statistical network model. Computational \& Mathematical Organization Theory, 5(2), 167- 192, 1999.

Breznik, K., \& Law, K. "How social networks affect the learning performance among engineering students." Technics Technologies Education Management, 10(2), 191-203, 2015.

Rosen, K. H., \& Krithivasan, K. "Discrete mathematics and its applications: with combinatorics and graph theory." Tata McGraw-Hill Education, 2012.

Hagberg, A., Swart, P., \& S Chult, D. "Exploring network structure, dynamics, and function using networkx (Tech. Rep.).” Los Alamos National Lab. (LANL), Los Alamos, NM (United States), 2008.

Rakhmanov, Ochilbek, \& Senol Dane. "The Effects of Self-Esteem, Friendship, Aggressiveness on Short and Long Visual Memories Assessed by ROCF Test." Journal of Research in Medical and Dental Science 8.3 (2020): 25-31.

Rakhmanov, O., \& S. Dane. "The relationships among gender, handedness, GPA, depression and visual memory in the ROCF test in university students." J Res Med Dent Sci 8 (2020): 37-42. 